\title{
The Underemployed: Evidence From the UK Labour Force Survey for a Conditionally Gendered Top-down Model
}

\author{
Surhan Cam \\ Cardiff University, UK \\ E-mail: CamS@cardiff.ac.uk
}

Received: December 11, 2013 Accepted: January 23, 2014 Published: February 11, 2014

doi:10.5296/jsss.v1i2.5101ＵRL: http://dx.doi.org/10.5296/jsss.v1i2.5101

\begin{abstract}
Systematic research into underemployment is limited in Britain and specific analyses of its relation to work-status are largely missing from the academic debate. The present study explores the impact of work-status on underemployment along with references to demographic indicators. We examine Labour Force Survey data through logistic regressions. Our results fit into what one might call a conditionally gendered top-down model: As measured by work-place characteristics, work-contracts and occupational levels, one's status at work inversely correlates with the likelihood of underemployment. Such a top-down propensity largely reflects a decline in demand for lower skills in the UK since the beginning of the recession in 2008. The model also has a gendered character which helps explain a relatively higher rise in female underemployment amid the economic downturn. However, this character rather takes a conditional form due to opposite gender disparities in different work settings. In female-dominated works including sales, customer services and part-time jobs, for example, women's underemployment is lower than men's, but it is higher in elementary occupations, especially because of glass-ceiling.
\end{abstract}

Keywords: Underemployment, Work-Status, Gender, Recession, Precarious Work

\section{Introduction}

This paper focuses on time-related underemployment rather than credentials underemployment -the gap between qualifications and jobs (Batenburg \& De Witte, 2001). Underemployment is occasionally defined in a subjective way by referring to workers' perceptions (Glyde, 1977; Jensen \& Slack, 2003; Bell \& Blanchflower, 2011). Even so, some additional specifications have been introduced in official definitions. The EU Working Time Regulations (HMSO, 2012) provide a 'constructed definition' for underemployment by excluding those who are working more than forty-eight hours per week (the threshold is forty 
hours for those younger than eighteen years of age). Such a definition arbitrarily overlooks certain individuals' perceptions (Hussmans, 2007), but it is widely regarded as an operable tool by academic discussants as well as policy makers (Walling \& Clancy, 2010). Accordingly, our analyses will cover only those who fall into the constructed definition of underemployment.

It is important to explore underemployment as a lack of systematic research in the UK remains at odds with the growing proportions of underemployed British workers since the beginning of the recession in 2008 , from circa $7 \%$ of all in employment to $11 \%$ in 2012 . In this period, the number of such workers has risen by almost one million, reaching just above three and a half million (LFS, 2008 \& 2012). The extra hours of work demanded by people are by no means residual. Almost $70 \%$ of the underemployed, for example, wished to have longer than eight extra hours per week in 2012 (LFS, 2012). Further pressures on job markets are also expected owing to widening cuts in public spending and cost-reduction strategies in the private sector (Hogarth et al., 2009).

The recent surge has strong policy implications, albeit underemployment had conventionally been considered to be a trade off with job retention (Lallement, 2011). It has caused concerns among trade unions, and the Trades Union Congress warned the government about the difficulties of finding long-enough hours of work (TUC, 2012). Unions' response is consistent with the international research findings over the negative influences of underemployment on life (Wilkins, 2007) and job satisfaction (Johnson and Johnson, 1995; Wooden et al., 2009). However, the issue is by no means less critical from a managerial point of view since underemployment mitigates, as it has been long pointed out, against labour productivity along with workers' motivations (Sullivan, 1978). International research has further elaborated its detrimental implications for wage incentives (Watson, 2002) and employees' commitment to companies (Abrahamsen, 2010). Available data in the UK also show that it urges workers to look for other jobs (Böheim \& Taylor, 2004; Bell \& Blanchflower, 2011).

Advancing systematic analyses on the dynamics of underemployment in the case of British labour market, in particular, may offer some specific contributions to the literature because of a distinctively higher proportion of part-time employment. Roughly 30\% of British employees work in part-time jobs (LFS, 2012), compared to less than $18 \%$ average in the G7 countries (OECD, 2010). Since the beginning of the recession in Britain, there has been an increase in involuntary part-time jobs -as defined by being unable to obtain full-time contracts (Cam, 2012). Research evidence from Denmark (Lind \& Rasmussen, 2008) and Norway (Kjeldstad \& Nymoen, 2012) also suggests that part-time jobs imply higher levels of underemployment. This may have additional implications for gender debates because of the disproportionate location of British women in part-time jobs. Over $45 \%$ of female employees work on a part-time contract which is almost double the average for the G7 countries (OECD, 2010).

Although to a lesser extent, systematic research specifically on the predictors of underemployment is also limited in the international literature, as discussed in what follows. Such a gap will be rectified in the present paper along with references to broader debates in relevant areas including involuntary part-time work (Glyde, 1977; Walling \& Clancy, 2010; 
Cam, 2012) and overemployment -characterised by a desire to work less (Golden \& Gebreselassie, 2007). For this purpose, we will suggest a 'conditionally gendered top-down model'. Before specifying the model, it would be useful to stipulate its main components, demographic and work-status profiles which are frequently referred to by the relevant debates in general. The former is comprised of marital status and age in addition to gender. The latter encompasses work-place characteristics, flexible work, trade union membership and task/job nominators (occupational and educational levels).

\subsection{Demographic Factors}

In Britain, various studies emphasised the benefits of shorter working times for women (Hakim, 1997; Massey, 1994; Siltanen, 1994). Hakim (1997), for example, contended that part-time contracts were preferred by women for their 'marriage career'. It was also reported that women part-time employees had more job satisfaction than men due to a better work-life balance (Bonney, 2005). However, the recent evidence points to a higher level of involuntariness among women for part-time jobs than men (Bell \& Blanchflower, 2011; Cam, 2012).

Research findings specifically on underemployment, on the other hand, suggested no gender difference at the beginning of the millennium, roughly 6\% (Simic, 2002). This was consistent with the evidence over the limited effect of gender on overemployment (MacInnes, 2005). Even so, underemployed women wished to have significantly longer extra hours than men (Stier \& Lewin-Epstein, 2003). More up-to-date research from various countries such as Australia (Wooden et al., 2009), the USA (Reynolds \& Aletraris, 2010) and Norway (Kjeldstad \& Nymoen, 2012) has also evidenced higher levels of underemployment among women than men.

As another demographic factor, the impact of dependent children on preferences for working times was illustrated in the case of involuntary part-time work. Having dependent children was reported to have been inversely related to involuntariness for part-time work among American (Leppel \& Clain, 1988) and Australian women (Walsh, 1999). Evidence from the international studies has further proved the importance of age and marriage specifically for underemployment. Ruiz-Quintanilla and Claes (1996), for example, highlighted a higher risk of underemployment among younger workers, as Bell and Blanchflower (2011) did in the UK. An aggregated analysis mostly over the EU and other developed countries also stressed that marriage diminished the likelihood of underemployment (Stier \& Lewin-Epstein, 2003).

\subsection{Work-Status Issues}

Various workplace characteristics were related to working time perceptions through involuntary part-time work and overemployment as well as underemployment in the international literature. For example, Caputo and Cianni (2001) referred to the less likelihood of involuntariness among part-time female employees in the US private companies since they were motivated to take part-time jobs for economic reasons rather than personal or professional edification. In the case of underemployment, the public/private sector division was also related to structural factors such as financial instabilities. Nosal (1998), among others, underlined that the public sector could keep underemployment at bay amongst its employees by deploying vast fiscal resources. 
Industrial differences regarding their influences on the mismatching of working times were addressed as well. For example, involuntariness for part-time contracts in Britain are concentrated in the industries where part-time (Bell \& Blanchflower, 2011) and low-pay jobs (Cam, 2012) are prominent. In terms of underemployment, Yotopoulos (1965) historically argued that as the rate of wages to productivity changed from one industry to another, underemployment displayed industrial variations. The evidence from Norway further demonstrated that underemployment was more common in female-dominated industries such as sales, services and care industries (Kjeldstad \& Nymoen, 2012).

Another workplace characteristic related to employees' discontent with working times is the size of establishments. One of the main reasons for this is the financial constraints on smaller companies largely owing to their spatial dependency on local trade (Edwards \& Ram, 2006). In Britain, Stewart and Swaffield (1997) showed that overemployment was higher in smaller establishments, compared to larger ones. This appears to be in line with the concerns over the disadvantages that employees experience in such workplaces with regard to overtime and family-friendly provisions (Dex \& Scheibl, 2001). Even so, Kjeldstad and Nymoen (2012) documented that the likelihood of underemployment was also higher in smaller Norwegian companies than it was in larger firms.

Research findings point to the importance of trade union membership with regard to unbalanced length of working times. In Canada, for example, Schellenberg (1995) reported that membership predicted a lower likelihood of involuntariness among part-time workers. Another investigation on Canadian workers in the early 1980s had also underlined that union membership helped reduce the likelihood of underemployment (Ham, 1982). Investigating the impact of membership on underemployment in the UK has become particularly important since the research evidence has begun to generate doubts about the benefits of unions' support for family-friendly initiatives (Gregory \& Milner, 2009; Rigby \& Smith, 2010).

Research in Britain documented that temporary workers had a higher propensity toward part-time jobs as a result of being unable to obtain full-time contracts (Cam, 2012). International literature linked temporary jobs to underemployment as well. In the USA, for example, Rogers (2001) established that temporary employment of assistant teachers had direct implications for underemployment because of the lay-off spells during quieter periods in return for offsetting the cost of labour. Likewise, evidence from Norway (Kjeldstad \& Nymoen, 2012) suggested that temporary workers often turn out to be underemployed as a response to their low pay.

Academic explorations into the relation of occupations to overemployment have been undertaken. International research evidence, for example, brought out that the desire for fewer hours was most common among employees who hold high-ranking occupations (Clarkberg \& Moen, 2001; Golden \& Gebreselassie, 2007; Jacobs \& Gerson, 2004). In Britain, MacInnes (2005) also suggested that this might be because such workers could afford to cut down their hours. In particular, the evidence from Norway indicated that underemployment was more pronounced in low skill occupations (Kjeldstad \& Nymoen, 2012).

Education is an important and complex indicator of people's positions at work (Brown et al., 2004). For example, when involuntary part-time employment rose to 16 million during the 
economic downturn of the 1970s, Bednarzik (1976) cited low education and skills as the main reasons in the USA. Among Australian female part-time workers, on the other hand, education was reported to have had no strong effect on involuntariness (Walsh, 1999). Further, research in the UK has contrarily pointed to higher education as a major cause of involuntariness for part-time jobs (Bell \& Blanchflower, 2011). Adding full-time workers into the equation in the USA, Reynolds and Aletraris (2010) evidenced that higher education together with high-ranking occupations gave employees a better chance to avoid underemployment. Likewise, aggregated results from developed countries highlighted that higher education reduced the likelihood of underemployment (Stier \& Lewin-Epstein, 2003).

Considering the debates reviewed so far, we will explore socio-economic predictors of underemployment under the overall frame of the conditionally gendered top-down model. Through the notion of a top-down occurrence, the model will suggest that the likelihood of underemployment is inversely related to one's status at work in general as measured by work-place characteristics in terms of industries, public/private sectors and establishment size; flexible work including part-time and temporary contracts; trade union membership and finally task/job nominators -occupational and educational levels. The model will also suggest that the top-down tendency exhibits a gendered character. However, this character may not necessarily manifest itself through a strong aggregated gap between men and women as it may rather turn out to be a conditional process -formed by opposite gender disparities in different demographic and work-related settings.

\section{Methods}

\subsection{Data}

Data is analysed from the UK Labour Force Survey, a large household-based survey conducted by the Office for National Statistics (ONS). We used the data from the final quarter (between October and December) of 2012, the latest round asking the trade union membership question. Even so, available data from the other quarters were also checked, but no substantial difference was found from the results reported in this paper.

LFS deploys a multi-stage sampling design to achieve a probability sample of households and individuals in Britain for the exploration of employees' labour market status (ONS, 2011). The major data collection instruments were face to face and telephone interviews with a small amount of postal surveys. Research is conducted with a worker or the representative of sample households on behalf of the workers investigated (proxy interview). A total of 106,643 questionnaires were filled. The survey typically achieved a response rate in the region of $85 \%$ (ONS, 2011). Various studies have shown that non-responders in surveys cannot be identified according to any socio-demographic factor, indicating that any biases introduced by non-response are not strongly related to commonly used explanatory variables (Chatzitheochari and Arber, 2009). Our dependent variable picked up 2,538 male and 3,108 female underemployed (out of 30,605 men and 30,748 women in employment).

\subsection{Dependent Variable: Wishing to Work Longer}

LFS asks participants about the extra hours they wish to work. First, we selected all respondents who wish to work longer (Jenkins \& Laux, 1999). However, we then filtered out, as noted earlier, those who are under 18 years of age but working more than 40 hours per 
week in addition to anyone working longer than 48 hours.

Two limitations should be borne in mind regarding the dependent variable of underemployment. It is based on the self-definitions of participants in LFS. Therefore there is no consistency about the definition of underemployment across the sample. The second constraint is that it is not possible to pin down how strongly people want to have extra hours (Hussmans, 2007). This is particularly important in a recessionary economy in which people may adjust their work expectations to tighter job markets (ONS, 2011).

\subsection{Independent Variables}

This study controls the relevance of underemployment to the five categories hitherto stipulated: demographic profiles, workplace characteristics, flexible work, union membership and task/job nominators.

Among the demographic variables, household type refers to the presence, or absence, of spouse/partner and dependent children (younger than 19 years old). The second demographic variable, age, is measured by recoding working age population (from 16 to 64 years old) into four brackets in line with common practices (Blanden \& Machin, 2003). Those over 64 years old are excluded due to a smaller cell size than the threshold advised by LFS, 25 before or 10,000 after grossing out (ONS, 2011:42)

Workplace characteristics (as well as flexible work and occupations) are based on the main jobs. Industries are derived from the international classification of SIC-2010 (Double-digit: Industry Sectors). Within 'manufacturing, energy and construction', 'energy' refers to mining, quarrying; electricity, gas, and water supply. Due to the small sample size, we dropped agriculture, forestry and fishing, whilst collapsing public administration, education and health together. The second variable within workplace characteristics is a dichotomous variable of respondents' self-report as to whether they work in the public or private sector. The third variable in this group, establishment size, refers to the number of co-workers reported by respondents, and it is collapsed into three bands: small $(<50)$, medium $(50-249)$ and large $(\geq$ 250) companies (Forth et al., 2006).

Flexible work variables are produced by breaking down respondents into part-time/full-time and temporary/permanent jobs, but their definitions may not be consistent as they reflect participants' perceptions.

Two caveats should be borne in mind regarding the independent variable of union membership. First, because the membership question is asked by the LFS only in the final quarter of each year, it is not possible to measure quarterly changes. Second, the wording of membership question refers to the membership of both trade unions and associations, although interviewers actually aim to find out trade union membership (Brook, 2001).

Among task/job nominators, occupations are compatible with their major level (single-digit) international classification (SOC-2010). We have used education levels as one of the task/job nominators in order to shed more light onto the impact of one's position at work on underemployment. Even so, because education is part of demographic characteristics, we first run our statistical analyses taking it within the demographic factors specified above. However, the results were not significantly different from the ones presented in this paper. Education refers to the highest qualification attained. 


\subsection{Analytical Technique}

The analysis uses logistic regression, which is widely employed when modelling binary outcomes and for predicting the probability of an event. The dependent dichotomous variable is whether or not participants wish to have extra hours of work. The binary response is yes/no. The logistic models predict the probability of wishing to work longer.

Independent variables are successively added to logistic models in sequential blocks, which allow the observation of changes in the predictors' relationship to the outcome variable and assessment of the relative importance of each predictor in the model. These blocks are designed to cover the five broader categories of independent variables: demographic profiles (household types and age), work-place characteristics (industry, public/private sectors and establishment size), flexible work (part/full-time and temporary/permanent jobs); trade union membership and finally task/job nominators (educational attainments and occupations). Neither the order of variables within the blocks nor that of blocks within the models makes a significant difference to the results. However, using household types and age for Model 1 and then adding work-place characteristics in Model 2 proved better than other combinations for the goodness of fit.

\section{Results}

\subsection{Descriptives}

Table 1 illustrates chi-square results for the variations between male and female workers' underemployment by demographic profiles, workplace characteristics, flexible work, trade union membership and task/job nominators. 
Table 1. The underemployed

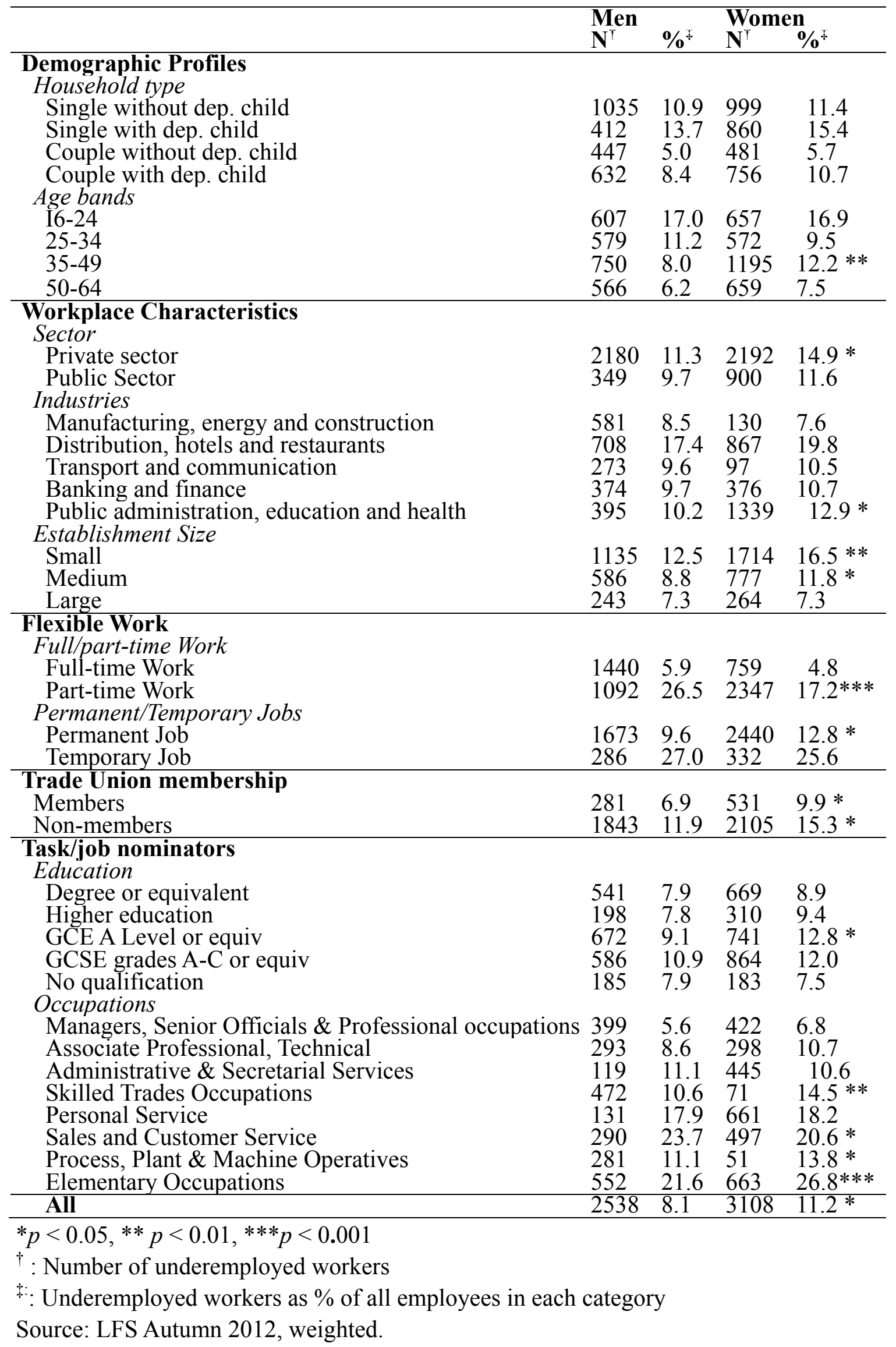


Household types reveal little discrepancies between men and women in terms of underemployment: Among single parents with dependent children, for example, the underemployment of both men and women is similarly around $15 \%$. The proportions also converge at circa 5\% among couples without dependent children. Age, on the other hand, points to a gender difference with some significance, but this only applies to those aged from 34 to 49 years old: $8 \%$ for men and slightly over $12 \%$ for women.

Private sector denotes more underemployment for female employees (15\%), compared to men (just above 11\%). Gender disparity, however, disappears in the public sector because of a decline in the proportion for women down to $11 \%$. Nor do industrial variations inform a substantial gender gap since the highest difference between men and women comes as $10 \%$ and $13 \%$ in the public administration, education and health, respectively. Although nearly $20 \%$ of women reported underemployment in distribution, hotels and restaurants, this does not amount to a significant gender gap as the figure for men also emerges above $17 \%$. When companies are taken on the basis of establishment size, the figures for men and women become more diverse, especially in smaller workplaces (almost 13\% of men and 17\% of women). To a lesser extent, the underemployment of men and women also vary in medium-sized companies, $9 \%$ and $12 \%$, respectively.

Reviewing part-time/full-time and temporary/permanent jobs comparatively gives further insight into underemployment by gender. There is little difference between full-time working men's and women's underemployment (circa 5\%) -unlike the gap among part-time working men $(27 \%)$ and women (17\%). Men's underemployment remains unchanged in temporary jobs, but the proportion for women also goes up to a similarly high level in such jobs (26\%). In permanent jobs, on the other hand, a residually significant difference becomes evident as the proportion for men goes down to below $10 \%$, compared to $13 \%$ for women.

Likewise, trade union membership suggests a marginally significant variation between male and female workers' underemployment (7\% and 10\%, respectively). Underemployment rises more or less proportionately among non-member men (12\%) and women (15\%).

Finally, we can have a look at the gender difference by task/job nominators, education and occupations. The only noticeable gender difference on the basis of educational attainments was observed at the GCSE A level or equivalent (secondary school): $9 \%$ of men and 13\% of women with such qualifications are underemployed. However, the gender divide becomes more salient in lower-ranking occupations. Circa $10 \%$ of men in skilled trade occupations are underemployed whereas the proportion is almost $15 \%$ for their female counterparts. The difference remains conspicuous whilst underemployment increases as we go down to the bottom category of occupations in the table: $22 \%$ of men and $27 \%$ of women are underemployed in elementary jobs.

Overall, underemployment is marginally higher among women (11.2\%) compared to men (8.1\%), but this occurs with a varying degree of influence across the demographic and work-related benchmarks considered. The gender difference also reverses in sales and customer services as well as in part-time jobs.

\subsection{Logistic Regression Models}

Both separate and joint logistic regression models to examine the differential effects of 
demographic and work-related circumstances on men's and women's underemployment are provided in Table 2. For each predictor variable, the last category in bivariate analyses is defined as the reference category.

Table 2. The underemployed

\begin{tabular}{|c|c|c|c|c|c|c|c|c|c|c|c|c|c|c|c|}
\hline \multirow{3}{*}{\begin{tabular}{|l|} 
Demographic profile \\
\end{tabular}} & \multicolumn{5}{|c|}{ Odds Ratios for All } & \multicolumn{5}{|c|}{ Odds Ratios for Men } & \multicolumn{5}{|c|}{ Odds Ratios for Women } \\
\hline & \multirow{2}{*}{ Model I } & \multirow{2}{*}{ Model II } & \multirow[t]{2}{*}{ Model IIII } & \multirow[t]{2}{*}{ Model IV } & \multirow[t]{2}{*}{ Model V } & \multirow[t]{2}{*}{ Model It } & \multirow[t]{2}{*}{ Model II } & \multirow[t]{2}{*}{ Model III } & \multirow[t]{2}{*}{ Model IV } & \multirow[t]{2}{*}{ Model V } & \multirow[t]{2}{*}{ Model In } & \multirow[t]{2}{*}{ Model II } & \multirow[t]{2}{*}{ Model III } & Model IVI & Model V \\
\hline & & & & & & & & & & & & & & & \\
\hline Household Type & $* * *$ & $* * *$ & *** & *** & $* * *$ & *** & $* * *$ & *** & *** & *** & $* * *$ & $* * *$ & $* * *$ & $* * *$ & $* * *$ \\
\hline Single without dep. child & $1.13^{* * * *}$ & $\mid 1.23^{* * *}$ & $1.73 * * *$ & $1.72^{* * *}$ & $1.57^{* * *}$ & 1.09 & $1.22 * * *$ & $1.18^{* * *}$ & $1.17^{* * *}$ & 1.05 & $1.13^{* * *}$ & $1.15^{* * *}$ & $2.19^{* * *}$ & $2.19^{* * *}$ & $2.03 * * *$ \\
\hline Single with dep. child & $1.39 * * *$ & * $1.55^{* * *}$ & $1.33^{* * * *}$ & $1.31^{* * *}$ & $1.28 * * *$ & $1.21 * * *$ & $1.25^{* * *}$ & 0.88 & 0.85 & 0.96 & $1.40^{* * * *}$ & $1.59 * * *$ & $1.69^{* * *}$ & $1.68 * * *$ & $1.56^{* * *}$ \\
\hline Couple without dep. child & $0.71 * * *$ & $* 0.74 * *$ & \begin{tabular}{|l|}
0.90 \\
\end{tabular} & $0.87 * * *$ & $0.86 * *$ & $0.76^{* * * *}$ & $0.83 * * *$ & $0.76^{* * *}$ & $0.74 * * *$ & $0.75 * * *$ & $0.64 * * *$ & $0.64 * * *$ & 0.99 & 0.95 & 0.92 \\
\hline Couple with dep. child & I & I & $\mathrm{I}$ & I & I & I & I & $\mathrm{I}$ & $\mathrm{I}$ & I & I & I & $\mathrm{I}$ & I & $\mathrm{I}$ \\
\hline \begin{tabular}{|l|} 
Age Bands \\
\end{tabular} & **** & **** & *** & $* * *$ & $* * *$ & $* * *$ & *** & $* * *$ & $* * *$ & **** & *** & $* * *$ & $* * *$ & $* * *$ & $* * *$ \\
\hline I6-24 & $2.16 * * *$ & $* 1.83^{* * * *}$ & $1.73 * * *$ & $1.69 * * *$ & & $2.67 * * *$ & $2.50 * * *$ & $1.81 * * *$ & $1.71 * * *$ & & $1.84 * * *$ & $1.47 * * *$ & $1.66^{* * *}$ & $1.68^{* * * *}$ & \\
\hline $25-34$ & $1.27 * * *$ & $1.17 * * *$ & $1.49^{* * * *}$ & $1.45^{* * *}$ & $1.45^{* * *}$ & $1.60^{* * * *}$ & $1.54^{* * *}$ & $1.95^{* * *}$ & $1.89^{* * *}$ & $1.98^{* * *}$ & 1.03 & 0.94 & $1.32 * * *$ & $1.29 * * *$ & $1.25^{* * *}$ \\
\hline $35-49$ & $1.35 * * *$ & $1.20^{* * *}$ & $1.51^{* * *}$ & $1.51^{* * * *}$ & $1.51^{* * *}$ & $1.20^{* * *}$ & 1.09 & $1.46^{* * *}$ & $1.41^{* * *}$ & $1.53^{* * *}$ & $1.45^{* * *}$ & $1.24 * * *$ & $1.66^{* * *}$ & $1.72 * * *$ & $1.62^{* * *}$ \\
\hline $50-64$ & $\mathrm{I}$ & I & \begin{tabular}{|l|}
$\mathrm{I}$ \\
\end{tabular} & I & $\mathrm{I}$ & $\mathrm{I}$ & $\mathrm{I}$ & $\mathrm{I}$ & $\mathrm{I}$ & $\mathrm{I}$ & $\mathrm{I}$ & I & I & \begin{tabular}{|l|}
$\mathrm{I}$ \\
\end{tabular} & I \\
\hline Workplace characteristics & & & & & & & & & & & & & & & \\
\hline Private Sector & & & & & & & & & & $0.78^{* * *}$ & & & & & \\
\hline Establishment Size & & $* * *$ & $* * *$ & $* * *$ & $* * *$ & & $* * *$ & $* * *$ & $* * *$ & $* * *$ & & $* * *$ & $* * *$ & $* * *$ & $* * *$ \\
\hline Small & & $1.93^{* * * *}$ & $1.62 * * *$ & $1.59^{* * *}$ & $1.39 * * *$ & & $1.58 * * *$ & $1.33^{* * *}$ & $1.32^{* * *}$ & $1.28^{* * *}$ & & $2.18^{* * *}$ & $1.87^{* * *}$ & $1.83^{* * *}$ & $1.51^{* * *}$ \\
\hline Medium & & $1.38 * * *$ & $1.30^{* * *}$ & $1.30^{* * *}$ & $1.13 * * *$ & & $1.16 * *$ & 1.05 & 1.07 & 1.02 & & $1.55^{* * *}$ & $1.51^{* * *}$ & $1.50 * * *$ & $1.20^{* * *}$ \\
\hline Large & & \begin{tabular}{|l|}
$\mathrm{I}$ \\
\end{tabular} & \begin{tabular}{|l|}
$\mathrm{I}$ \\
\end{tabular} & $\mathrm{I}$ & $\mathrm{I}$ & & I & $\mathrm{I}$ & I & I & & I & I & \begin{tabular}{|l|}
$\mathrm{I}$ \\
\end{tabular} & $\mathrm{I}$ \\
\hline Industries & & $* * *$ & *** & $* * *$ & *** & & $* * *$ & $* * *$ & $* *$ & & & $* * *$ & *** & $* * *$ & **** \\
\hline Manuf, energy and const & & $0.52 * * *$ & 0.91 & $0.83 * * *$ & $0.74 * * *$ & & $0.64 * * *$ & 0.97 & 0.87 & & & $0.53 * * *$ & $0.65^{* * *}$ & $0.64 * * *$ & $0.60 * * *$ \\
\hline Dist, hotels and restaurants & & $1.29 * * *$ & $1.26 * * *$ & $1.15^{* * * *}$ & \begin{tabular}{|l|}
0.93 \\
\end{tabular} & & $1.45^{* * * *}$ & $1.24 * * *$ & 1.11 & & & $1.34 * * *$ & $1.11 * * *$ & 1.02 & 0.90 \\
\hline Transport and communic & & $0.70^{* * * *}$ & 1.07 & 1.02 & 0.80 & & $0.84 * * *$ & 1.05 & 1.00 & & & $0.78 * *$ & 0.87 & 0.82 & $0.74 *$ \\
\hline Banking and finance & & $0.64 * * *$ & $0.83^{* * *}$ & $0.76^{* * * *}$ & $0.76^{* * *}$ & & $0.73 * * *$ & 0.91 & $0.83 *$ & & & $0.66^{* * *}$ & $0.73^{* * *}$ & $0.66^{* * * *}$ & $0.68^{* * *}$ \\
\hline Public adm, educ \& health & & \begin{tabular}{|l|}
$\mathrm{I}$ \\
\end{tabular} & \begin{tabular}{|l|}
$\mathrm{I}$ \\
\end{tabular} & I & I & & \begin{tabular}{l|}
$\mathrm{I}$ \\
\end{tabular} & $\mathrm{I}$ & $\mathrm{I}$ & & & I & I & \begin{tabular}{|l|}
$\mathrm{I}$ \\
\end{tabular} & I \\
\hline Flexible Work & & & & & & & & & & & & & & & \\
\hline Part-time Jobs & & & $5.26 * * *$ & $5.26^{* * *}$ & $4.54 * * *$ & & & $9.09 * * *$ & $9.09 * * *$ & $8.33^{* * *}$ & & & $5.26^{* * * *}$ & $5.26^{* * * *}$ & $4.76^{* * * *}$ \\
\hline Temporary Jobs & & & $1.88^{* * * *}$ & $1.88^{* * *}$ & $2.27 * * *$ & & & $2.00^{* * * *}$ & $1.96^{* * *}$ & $2.22 * * *$ & & & $1.66^{* * * *}$ & $1.69 * * *$ & $2.17 * * *$ \\
\hline Union Membership & & & & $0.82 * * *$ & $0.81 * * *$ & & & & $0.78^{* * * *}$ & $0.63^{* * *}$ & & & & $0.86^{* * * *}$ & \\
\hline Task/job nominators & & & & & & & & & & & & & & & \\
\hline Education & & & & & & & & & & & & & & & $* * *$ \\
\hline Degree or equivalent & & & & & & & & & & & & & & & $1.50^{* * * *}$ \\
\hline Higher education & & & & & & & & & & & & & & & $1.47 * * *$ \\
\hline GCE A Level or equiv & & & & & & & & & & & & & & & $1.41 * * *$ \\
\hline GCSE grades A-C or equiv & & & & & & & & & & & & & & & $1.41^{* * * *}$ \\
\hline No qualification & & & & & & & & & & & & & & & I \\
\hline Occupations & & & & & \begin{tabular}{|c|}
$* * *$ \\
\end{tabular} & & & & & $* * *$ & & & & & $* * *$ \\
\hline Managers, Sen Official \& Pro & & & & & $0.37 * * *$ & & & & & $0.47^{* * *}$ & & & & & $0.27^{* * *}$ \\
\hline Assoc. Prof, Technical & & & & & $0.47 * * *$ & & & & & $0.59 * * *$ & & & & & $0.37 * * *$ \\
\hline Admin \& Secret & & & & & $0.44 * * *$ & & & & & $0.72 * *$ & & & & & $0.40^{* * * *}$ \\
\hline Skilled Trades Occupations & & & & & $0.76 * * *$ & & & & & 0.81 & & & & & $0.67 * *$ \\
\hline Personal Service & & & & & $0.79 * * *$ & & & & & 1.31 & & & & & $0.68 * *$ \\
\hline Sales and Customer Service & & & & & $0.66 * *$ & & & & & 0.97 & & & & & $0.64 * *$ \\
\hline Proc, Plant \& Mach Ops & & & & & 0.86 & & & & & 0.91 & & & & & 1.01 \\
\hline Elementary Occupations & & & & & $\mathrm{I}$ & & & & & $\mathrm{I}$ & & & & & I \\
\hline$\Delta \mathrm{df}$ & 6 & 8 & 8 & 8 & 8 & 6 & 8 & 8 & 8 & 8 & 7 & 8 & 8 & 8 & 8 \\
\hline-2 LLR & 35487.9 & 25487.9 & 22842.0 & 19311.3 & 13789.4 & 16308.4 & 11137.8 & 9677.1 & 8117.6 & 5597.7 & 19064.4 & 14237.8 & 12933.6 & \begin{tabular}{|c|}
10995.7 \\
\end{tabular} & 8025.1 \\
\hline$\Delta-2 \mathrm{LRR}$ & & 10000.0 & 2645.9 & 3530.7 & 5521.9 & & 5170.6 & 1460.7 & 1559.5 & 2519.9 & & 4826.6 & 1304.2 & 1937.9 & 2970.6 \\
\hline Significance of $\Delta-2$ LRR & & & $* * *$ & $* * *$ & **** & & **** & $* * *$ & *** & $* * *$ & & & $* * *$ & *** & **** \\
\hline
\end{tabular}

Source: LFS Autumn 2012, weighted.

Significance of difference from the reference category $* p<0.05, * * p<0.01,{ }^{*} * p<0.001$. 
Model 1 includes demographic profiles in terms of household types and age brackets. Household types are strong predictors of underemployment regardless of gender. Singles without dependent children, for example, present a higher likelihood of underemployment $(\mathrm{OR}=1.39, p<0.001)$, compared to couples with dependent children -the reference category (Table 2). Couples without dependent children, on the other hand, display a less likelihood $(\mathrm{OR}=0.71, p<0.001)$.

Model 1 also shows that age has a significant effect, but it comes in a linear fashion only for male employees $(p<0.001)$. Those who are younger than the reference category of 50-64 years old are more likely to become underemployed with the exception of women aged from 25 to 34 years old.

Model 2 brings in workplace characteristics, public/private sectors, establishment size and industries. This model failed to detect a significant difference between the public and private sectors in terms of explaining the likelihood of underemployment. However, the latter two workplace characteristics turned out to be strong predictors for both men and women. The likelihood of wishing to work for longer hours, for example, is almost doubled in smaller establishments than it is in the larger ones $(\mathrm{OR}=1.93, p<0.001)$. Although to a smaller extent, the likelihood is also significantly higher in distribution, hotels and restaurants, compared to public administration, education and health $(\mathrm{OR}=1.29, p<0.001)$. The tendency toward underemployment, on the other hand, is lower in various industries such as manufacturing, energy and construction $(\mathrm{OR}=0.52, p<0.001)$ as well as banking and finance $(\mathrm{OR}=0.64, p<0.001)$.

It is worth mentioning that one needs to take workplace characteristics on board in order to assess demographic influences more accurately: Model 2 significantly consolidated the impact of being single without dependent children whilst weakening that of being aged from 35 to 39 years old for men (see the change in log-likelihood ratio in Table 2).

Model 3 incorporates flexible employment into the analysis through part-time/full time and temporary/permanent jobs. The model evidences that flexible works predict a higher likelihood of involuntariness regardless of gender $(p<0.001)$. The likelihood of underemployment is nearly twice higher in temporary jobs than it is in permanent jobs $(\mathrm{OR}=$ 1.88). Part-time work, however, is a stronger factor as it means more than five times higher likelihood of underemployment for female workers $(\mathrm{OR}=5.26)$ and almost twice as much as that for male participants $(\mathrm{OR}=9.09)$, compared to full-time jobs.

Model 3 eradicated the significance of some demographic and workplace-related factors, indicating that they were basically a reflection of flexible work. For men, these factors include being single with dependent children and working in manufacturing, energy, construction, transport, communication, banking, finance and medium-sized establishments. In the case of women, the same can also be said of being coupled without dependent children and working in transport and communication. The model, on the other hand, revealed the significance of being aged from 35 to 49 years old for men and from 25 to 34 years old for women.

Model 4 adds trade union membership which implies a lower likelihood of underemployment for both male $(\mathrm{OR}=0.78, p<0.001)$ and female respondents $(\mathrm{OR}=0.86, p<0.001)$, 
compared to non-members. The inclusion of trade union membership negated the significance of working in distribution, hotels and restaurants for both men and women. It did, however, render being a couple without dependent children significant in the joint model.

Model 5 includes task/job nominators to examine how the constraints stemmed from the educational and occupational profiles impinge upon the chances of employees to secure well-balanced working hours. The model puts all independent variables into the analysis together. We originally failed to find a significant relationship between educational attainments and the likelihood of underemployment. Then, we exhausted various combinations to avoid missing out educational influences. To control the dilution of education's effect by (the schooling) age in particular, we re-run the model without the youngest age bracket (16-24 years old). Our efforts were to no avail in the case of male participants, but isolating the youngest group brought out the impact of education on women (with no significant change on any other result presented in Table 2): Female workers who have GCSE grades A-C or above are more likely to become underemployed, compared to those who have no qualifications.

As for the occupational influences, when employees acquire higher-ranking jobs, underemployment becomes less likely $(p<0.001)$. In managerial, senior official and professional groups, for example, both men $(\mathrm{OR}=0.47)$ and women $(\mathrm{OR}=0.27)$ are exposed to a considerably smaller risk of underemployment, compared to the ones in elementary occupations.

Finally, the inclusion of task/job nominators eradicated the significant influence of distribution, hotels and restaurants in the joint model and that of union membership in the women's model. It, on the other hand, shed light on the role of the private sector in diminishing men's appetite to work longer.

\section{Conclusions}

To address the dearth of systematic research in the UK, we explored socio-economic predictors of underemployment. The likelihood of wishing to have extra hours of work is significantly affected by a range of correlates we considered. The results fit into our conditionally gendered top-down model. The evidence proved each one of three main components within the model, the top-down character of unemployment, the gendered nature of top-down process and the conditionality of gendering.

First, the top-down component of the model revealed that one's status at work inversely correlated with the likelihood of underemployment by and large. The logistic analyses highlighted a strong relationship between underemployment and some commonly used variables to understand labour standards including industrial variations, establishment size and flexible work. Low-pay jobs in, for example, hotels and restaurants boost the likelihood of underemployment, confirming previous studies (Kjeldstad \& Nymoen, 2012; Yotopoulos, 1965). Likewise, smaller establishments predict higher levels of underemployment in line with concerns over employees' well-being in such workplaces (Dex \& Scheibl, 2001; Edwards \& Ram, 2006). In addition, flexible works raise underemployment, corresponding with the international research findings over the impacts of part-time (Kjeldstad \& Nymoen, 2012; Lind \& Rasmussen, 2008) and temporary (Rogers, 2001) contracts. 
More evidence over the top-down propensity came from the task/job nominators. Compared to lower ranking occupations, higher ones significantly reduce underemployment among both male and female workers -whilst enhancing overemployment (MacInnes, 2005). This is much contributed to by a demand swing in the British economy from lower to higher skills since the beginning of the recession. Total usual hours of work in elementary occupations, for example, slumped more than $30 \%$ between 2007 and 2012 whereas there was circa $20 \%$ increase in professional occupations (LFS, 2007 \& 2012). However, the negative correlation between occupational levels and underemployment appears to be a structural, rather than a cyclical, effect. In 2007, for example, underemployment was below 5\% among managerial, professional and senior officials, whereas the proportion was twice as much as that for process, plant and machine operatives as well as elementary jobs (LFS, 2007).

The inverse relation of underemployment to occupations, in particular, implies a work-status inconsistency. The reason for this is because although higher occupations help alleviate underemployment, higher educational attainments have no impact on the British employees in general. Thus, our findings fail to confirm the preventative impact of higher education on underemployment among the EU and other developed countries (Stier \& Lewin-Epstein, 2003). The divergence in Britain partly reflects the issue of credentials underemployment (Batenburg \& De Witte, 2001). There has been a growing inconsistency between occupational and educational levels over the past decades due to a long-term inflation in over qualification and managerial layers (Brown, 2004; Brynin, 2002; Felstead et al., 2007).

As the second component of our model, the gendered character of the top-down process was also proven by the evidence. In terms of work-status inconsistency, for example, higher educational attainments display no impact on men but a negative effect on women. That is, higher educated women are more likely to become underemployed compared to those who have lower or no qualification. This accentuation of work-status inconsistency in the case of women is arguably attributable to a glass ceiling against their access to high-ranking occupations (Buchel \& Battu, 2003; Maume, 1999). Disproportionate location of younger women in part-time jobs is an important reason for such an outcome (Durbin and Tomlinson, 2010) as holding a degree, for example, doubles women's underemployment on part-time contracts, compared to having no qualification, 20\% (LFS, 2012).

The gendered nature of the top-down process in general challenges the notion of more preparedness among women for less work due to, inter alia, family commitments and self-fulfilment (Massey, 1994; Siltanen, 1994). The evidence suggested that women did not have a lower tendency toward underemployment, compared to men and, if anything, it has turned out to be somewhat the other way around since the beginning of the recession. Such a result is affected by a number of factors, in addition to education. Unlike the Canadian case (Ham, 1982), for example, union membership does not diminish British women's underemployment due to their limited chance to benefit from union agreements with management (Cam, 2011). Nor do private sector companies in the UK lessen women's underemployment, as opposed to the US experience (Caputo \& Cianni, 2001). It is important to keep in mind that the recessionary decline in demand for low skills has worse affected women, not least because they fill two-thirds of elementary jobs (LFS, 2012). Dwindling welfare provisions for childcare also had an enhancing effect on single mothers' desire for 
extra work (Forry \& Hofferth, 2011).

Finally, the gendering of top-down process presented a conditional character as it was predicated on demographic and work-related specificities -rather than a strong gender gap at the aggregated level. Notably, women have lower levels of underemployment than men in female-dominated works such as sales, customer services and part-time jobs in general (Caputo \& Cianni, 2001; Kjeldstad \& Nymoen, 2012). This can be attributed to the gendered division of labour both at home and work (Booth and Ours, 2009; Hakim, 1997; Webber and Williams, 2008). Households with a cohabiting couple and dependent children, for instance, reduce the likelihood of underemployment among women, whereas they have an opposite effect on men. Such a result, in particular, does not seem to sit happily with women's higher involuntariness for part-time jobs than men's (Bell \& Blanchflower, 2011; Cam, 2012). However, those women who want full-time contracts with no extra hours already work as long as one in four men in full-time jobs, 33 hours per week on average (LFS, 2012).

Broadly speaking, underemployment fits into a conditionally gendered top-down model. Its top-down character is comprised of an inverse correlation with one's status at work as measured by workplace characteristics, contracts and occupational levels. This resonates with a slump in demand for lower skills since the beginning of the recession. Meanwhile, the process has materialised itself through a conditional gendering as a marginally higher raise in women's aggregated underemployment turned out to be a mediated outcome between a more pronounced female underemployment in low skill occupations and reverse appearances in female-dominated works.

Recent attempts to curtail the government funds for childcare through the tax credit system may augment underemployment further, particularly among women (Forry \& Hofferth, 2011). Such a situation would add to the rising proportion of men in the service sector amid the recessionary erosion of female-dominated occupations (Hogarth et al., 2009). To combat the current economic downturn successfully, the government should try to contain the spread of underemployment as it undermines life satisfaction (Wilkins, 2007), job satisfaction (Johnson \& Johnson, 1995; Wooden et al., 2009), work commitment (Abrahamsen, 2010) and labour productivity (Sullivan, 1978). For this purpose, policy makers should consider a fuller adoption of the EU directives to empower employees in negotiating work arrangements with management (Butler, 2009; Forde \& Slater, 2005). Unions also need to be more effective in terms of delivering dividends to workers from their interventions in working times (Gregory \& Milner, 2009; Rigby \& Smith, 2010).

The negative relation of underemployment to job levels offers an empirically and conceptually fertile ground for the precarious employment debates (Kalleberg, 2009; Pape, 2008). There is, however, a need for specific analyses to examine the relationship between underemployment and some potentially important issues which are not covered in this study such as participation and earnings (Watts, 2010). Besides, it would be useful to conduct qualitative research in order to develop an in-depth insight into, for example, the ways in which variations in household types, demographic profiles and educational attainments culturally inform underemployment. 


\section{References}

Abrahamsen, B. (2010). Employment Status and Commitment to Work in Professions. Economic and Industrial Democracy, 31(1), 93-115. http://dx.doi.org/10.1177/0143831X09343990

Batenburg, R., \& De Witte, M. (2001). Underemployment in the Netherlands: How the Dutch "Poldermodel" Failed to Close the Education-Jobs Gap. Work Employment and Society, 15(1), 73-94. http://dx.doi.org/10.1177/09500170122118788

Bednarzik, R. W. (1976). Involuntary Part-Time Work and Educational Attainment. The Journal of General Education, 28(2), 135-43.

Bell, N. F. D., \& Blanchflower, D. (2011). Underemployment in the UK in the Great Recession. National Institute Economic Review, 215, 25-33. http://dx.doi.org/10.1177/0027950111401141

Blanden, J., \& Machin, S. (2003). Cross-Generation Correlations of Union Status for Young People in Britain. British Journal of Industrial Relations, 41(3), 391-415. http://dx.doi.org/10.1111/1467-8543.00279

Böheim, R., \& Taylor, M. P. (2004). Actual and preferred working hours. British Journal of Industrial Relations, 42, 149-66. http://dx.doi.org/10.1111/j.1467-8543.2004.00308.x

Bonney, N. (2005). Overworked Britons? Part-time work and Work-life balance. Work, Employment and Society, 19(2), 391-401. http://dx.doi.org/10.1177/0950017005053182

Booth A. L., \& Ours, J. C. Van (2009). Hours of Work and Gender Identity: Does Part-time Work Make the Family Happier? Economica, 76, 176-96. http://dx.doi.org/10.1111/j.1468-0335.2007.00670.x

Brook, K. (2001). Trade union membership: an analysis of data from the autumn 2001 LFS. Labour Market Trends - July 2002: National Statistics Feature.

Brown, P., Hesketh, A., \& Williams, S. (2004). Mismanagement of Talent: Employability and Jobs in the Knowledge Economy. Oxford: Oxford University Press. http://dx.doi.org/10.1093/acprof:oso/9780199269532.001.0001

Brynin, M. (2002). Overqualification in employment. Work, Employment and Society, 16(4), 637-54. http://dx.doi.org/10.1177/095001702321587406

Buchel, F., \& Battu, H. (2003). The theory of differential overqualification: does it work? Scottish Journal of Political Economy, 50(1), 1-16. http://dx.doi.org/10.1111/1467-9485.00251

Butler, P. (2009). Non-union employee representation: exploring the riddle of managerial strategy. Industrial Relations Journal, $40(3), \quad 198-214$. http://dx.doi.org/10.1111/j.1468-2338.2009.00521.x 
Cam, S. (2011). Unincluded Trade Union Members: Evidence from the Labour Force Survey. Cardiff: Cardiff University Working Papers.

Cam, S. (2012). Involuntary Part-time Work in Britain: Evidence from the Labour Force Survey. Industrial Relations Journal, 43(3), 242-60.

Caputo, R. K., \& Cianni M. (2001). Correlates of Voluntary vs. Involuntary Part-time Employment among US Women. Gender, Work and Organization, 8(3), 311-25. http://dx.doi.org/10.1111/1468-0432.00134

Chatzitheochari, S., \& Arber, S. (2009). Lack of sleep, work and the long hours culture: evidence from the UK Time Use Survey. Work, Employment and Society, 23(1), 30-48. http://dx.doi.org/10.1177/0950017008099776

Clarkberg, M., \& Moen, P. (2001). Understanding the time-squeeze: Married couples' preferred and actual work-hour strategies. American Behavioural Scientist, 44, 1115-36. http://dx.doi.org/10.1177/0002764201044007005

Dex, S., \& Scheibl, F. (2001). Flexible and Family-Friendly Working Arrangements in UK-Based SMEs: Business Cases. British Journal of Industrial Relations, 39(3), 411-31. http://dx.doi.org/10.1111/1467-8543.00207

Durbin, S., \& Tomlinson, J. (2010). 'Female part-time managers'. Work, Employment and Society, 24(4), 621-41. http://dx.doi.org/10.1177/0950017010380631

Edwards, P., \& Ram, P. (2006). Surviving on the Margins of the Economy: Working relationships in Small, Low-Wage Firms. Journal of Management Studies, 43(4), 895-916. http://dx.doi.org/10.1111/j.1467-6486.2006.00615.x

Felstead, A., Gallie, D., Green, F., \& Zhou, Y. (2007). Skills at Work: 1986-2006. Cardiff: ESRC Centre for Skills, Knowledge and Organisational Performance.

Forde, C., \& Slater, G. (2005). Agency Working in Britain: Character, Consequences and Regulation. British Journal of Industrial Relations, 43(2), 249-71. http://dx.doi.org/10.1111/j.1467-8543.2005.00354.x

Forry, N. D., \& Hofferth, S. L. (2011). Maintaining Work: The Influence of Child Care Subsidies on Child Care-related Work Disruptions. Work, Employment and Society, 32(3), 346-68.

Forth, J., Bryson, A., \& Bewley, H. (2006). Small and medium-sized enterprises: Findings from the 2004 workplace employment relations survey, London: Department of Trade and Industry.

Glyde, G. P. (1977). Under-employment: definition and causes. Journal of Economic Issues, 11(2), 245-61.

Golden, L., \& Gebreselassie, T. (2007). Overemployment mismatches: The preference for fewer work hours. Monthly Labor Review, 130(4), 18-37. 
Gregory, A., \& Milner, S. (2009). Trade Unions and work-life Balance: Changing Times in France and the UK? British Journal of Industrial Relations, 41(7), 122-46. http://dx.doi.org/10.1111/j.1467-8543.2008.00710.x

Hakim, C. (1997). A sociological perspective on part-time work. In H-P Blossfeld \& C. Hakim (Eds), Between Equalization and Marginalization: Women Working Part-Time in Europe and the United States of America (pp. 22-70). Oxford: Oxford University Press.

Ham, J. C. (1982). Estimation of a labour supply model with censoring due to unemployment and underemployment. Review of Economic Studies, 49, 335-54. http://dx.doi.org/10.2307/2297360

HMSO, Her Majesty's Stationary Office. (2012). The Working Time Regulations 1998. Retrieved from http://www.legislation.gov.uk/uksi/1998/1833/contents/made

Hogarth, T., Owen, D., Gambin, L., Hasluck, C., Lyonette, C., \& Casey, B. (2009). The equality impacts of the current recession. Manchester: Equality and Human Rights Commission Research Report. No: 47.

Hussmans, R. (2007). Measurement of employment, unemployment and underemployment -current international standards and issues in their application. Geneva: ILO Bureau of Statistics.

Jacobs, J. A., \& Gerson, K. (2004). The time divide: Work, family, and gender inequality. Cambridge, MA: Harvard University Press.

Jenkins, J., \& Laux, R. (1999). Using the Labour Force Survey to estimate time-related underemployment. Labour Market Trends, 417-23.

Jensen, L., \& Slack, T. (2003). Under-employment in America: measurement and evidence. American Journal of Community Psychology, 32(2), 21-31. http://dx.doi.org/10.1023/A:1025686621578

Johnson, G., \& Johnson, W. R. (1995). Subjective under-employment and job satisfaction. International Review of Modern Sociology, 25, 73-84.

Kalleberg, A. (2009). Precarious Work, Insecure Workers: Employment Relations in Transition. American Sociological Review, 74(1), 1-22. http://dx.doi.org/10.1177/000312240907400101

Kjeldstad, R., \& Nymoen, H. (2012). Underemployment in a gender-segregated labour market. Economic and Industrial Democracy, 33(2), 207-24. http://dx.doi.org/10.1177/0143831X11402238

Lallement, M. (2011). Europe and the economic crisis: forms of labour market adjustment and varieties of capitalism. Work, Employment and Society, 25(4), 627-41. http://dx.doi.org/10.1177/0950017011419717

LFS (2000, 2007/8 \& 2012). UK Data Archive Labour Force Survey, Autumn Quarters. Retrieved from http://www.esds.ac.uk/findingData/snDescription.asp?sn=6413 
Lind, J., \& Rasmussen, E. (2008). Paradoxical patterns of part-time employment in Denmark. Economic and Industrial Democracy, 29(4), 521-40. http://dx.doi.org/10.1177/0143831X08096226

MacInnes, J. (2005). Work-Life Balance and the Demand for Reduction in Working Hours: Evidence from the British Social Attitudes Survey 2002. British Journal of Industrial Relations, 43(2), 273-95. http://dx.doi.org/10.1111/j.1467-8543.2005.00355.x

Massey, D. (1994). Masculinity, Dualism and High Technology. Transactions of the Institute of British Geographers, 20(87), 487-99.

Maume, D. J. J. (1999). Glass ceilings and glass escalators: occupational segregation and race and sex differences in managerial promotions. Work and Occupations, 26(4), 483-509. http://dx.doi.org/10.1177/0730888499026004005

Millar, J., Ridge, T., \& Bennett, F. (2006). Part-time Work and Social Security: Increasing Options. Norwich: Department for Work and Pensions.

Nosal, E. (1998). Financial Distress and Underemployment. Review of Economic Studies, 65, 817-45. http://dx.doi.org/10.1111/1467-937X.00070

OECD. (2010). Employment Outlook: Moving Beyond the Jobs Crisis. Geneva: OECD Publications.

ONS, Office for National Statistics. (2011). Labour Force Survey User Guide. Retrieved from http://www.esds.ac.uk/findingData/snDescription.asp?sn=6404

Pape, K. (2008). Precarious Employment and Flexicurity - the perspective of a (trade union orientated) user of statistics. Retrieved from http://www.wiego.org/reports/statistics/nov-2008/Pape.pdf

Reynolds, J., \& Aletraris, L. (2010). Mostly Mismatched with a Chance of Settling: Tracking Work Hour Mismatches in the United States. Work and Occupations, 37(4), 476-511. http://dx.doi.org/10.1177/0730888410383245

Rigby, M., \& O'Brien-Smith, F. (2010). Trade union interventions in work-life balance. Work, Employment and Society, 24(2), 203-20. http://dx.doi.org/10.1177/0950017010362145

Rogers, J. K. (2001). There's No Substitute: The Politics of Time Transfer in the Teaching $\begin{array}{llll}\text { Profession. Work } \quad \text { Ond } & \text { Occupations, }\end{array}$ http://dx.doi.org/10.1177/0730888401028001005

Ruiz-Quintanilla, S. A., \& Claes, R. (1996). Determinants of underemployment of young adults: a multi-country study. Industrial and Labor Relations Review, 45(5), 424-38. http://dx.doi.org/10.2307/2524195

Schellenberg, G. (1995). Involuntary Part-time Workers. Perception, 28, 3-4.

Siltanen, J. (1994). Locating Gender, Occupational Segregation, Wages and Domestic Responsibilities. London: UCL Press. 
Simic, M. (2002). Underemployment and Overemployment in the UK. Labour Market Trends, $110(8), 399-414$.

Stewart, M. B., \& Swaffield, J. (1997). Constraints on the desired hours of work of British men. Economic Journal, 107, 520-35. http://dx.doi.org/10.1111/j.0013-0133.1997.175.x

Stier, H., \& Lewin-Epstein, N. (2003). Time to work: a comparative analysis of preferences for working hours. Work and Occupations, 30, 302-26. http://dx.doi.org/10.1177/0730888403253897

Sullivan, T. A. (1978). Marginal Workers, Marginal Jobs-The Under-utilization of American Workers. Texas: University of Texas Press.

TUC. (2012). Male under-employment has doubled over the last four years. London: TUC Report.

Walling, A., \& Clancy, G. (2010). Underemployment in the UK labour market. Economic \& Labour Market Review, 4(2), 16-24. http://dx.doi.org/10.1057/elmr.2010.21

Walsh, J. (1999). Myths and Counter-Myths: An Analysis of Part-Time Female Employees and Their Orientations to Work and Working Hours. Work, Employment and Society, 13(2), 179-203. http://dx.doi.org/10.1017/S095001709900015X

Watson, I. (2002). Wage inequality and under-employment: Australia in the 1990s. The Journal of Industrial Relations, $44(1), \quad 88-107$. http://dx.doi.org/10.1111/1472-9296.00038

Watts, M. (2010). How Should Minimum Wages be Set in Australia? The Journal of Industrial Relations, 52(2), 131-49. http://dx.doi.org/10.1177/0022185609359441

Wilkins, R. (2007). The consequences of under-employment for the under-employed. Journal of Industrial Relations, 49(2), 247-75. http://dx.doi.org/10.1177/0022185607074921

Webber, G., \& Williams, C. (2008). Part-Time Work and the Gender Division of Labor. Qualitative Sociology, 31, 15-36. http://dx.doi.org/10.1007/s11133-007-9088-3

Wooden, M., Warren, D., \& Drago, R. (2009). Working Time Mismatch and Subjective Well-being. British Journal of Industrial Relations, 47(1), 147-79. http://dx.doi.org/10.1111/j.1467-8543.2008.00705.x

Yotopoulos, P. A. (1965). The "Wage-Productivity" Theory of Underemployment: A Refinement. Review of Economic Studies, 32(1), 59-66. http://dx.doi.org/10.2307/2296332

\section{Copyright Disclaimer}

Copyright reserved by the author(s).

This article is an open-access article distributed under the terms and conditions of the Creative Commons Attribution license (http://creativecommons.org/licenses/by/3.0/). 